\title{
Left ventricular functions and mass of the adolescents and young adults with thalassemia major: An echocardiography study
}

\author{
Muhammad Ali, Sukman Tulus Putra, Djajadiman Gatot, Sudigdo Sastroasmoro
}

\begin{abstract}
Background Thalassemia major (TM) is a transfusion-dependent disease. Multiple transfusions cause an accumulation of iron in the body. On the heart, iron can induce cardiomyopathy, the leading cause of death in TM.

Objective To evaluate left ventricular functions and mass among adolescents and young adults with TM.

Methods A cross-sectional study was conducted on 58 patients with TM in Cipto Mangunkusumo Hospital, Jakarta. Hematological data was collected from medical record. Left ventricular systolic functions (EF, FS), diastolic functions (A, E, E/A ratio, IVRT), and mass (LVDDi, LVDSi, LVMi) were detected using an echocardiography Sonos 4500 . T test, linier regression, and multiple regression analysis were performed.

Results Out of 32 TM patients, 30 were enrolled to study. Left ventricular systolic and diastolic functions of TM patients were lower than those of the control and statistically significant [EF 66.1\% (SD 4.9) and $71.6 \%$ (SD 5.6); P<0.0001, FS 36.0\% (SD 3.7) and 39.8\% (SD 5.5); $P=0.003$, E/A 2.14 (SD 0.4) and 1.83 (SD 0.3); $P=0.002$, respectively]. Left ventricular mass of TM patients was greater than that of control, and also statistically significant [LVMi $111.1 \mathrm{~g} / \mathrm{m}^{2}$ (SD 30.8) and $75.4 \mathrm{~g} / \mathrm{m}^{2}$ (SD 14.5); $P<0.0001$, respectively]. Linier and multiple regression analysis showed significant and powerful correlation between left ventricular diastolic functions (E/A ratio) and serum ferritin concentration $(r=0.71 ; P<0.0001)$.

Conclusion Left ventricular functions and mass of adolescents and young adults with TM show abnormalities. The higher the concentration of ferritin serum is, the more likely for TM patient to suffer from diastolic abnormality [Paediatr Indones 2006;46:214-219].
\end{abstract}

Keywords: thalassemia major, left ventricular functions and mass, ferritin serum concentration
$\mathrm{T}$ halassemia $\beta$ major (TM) is an inherited hemoglobin disorder caused by failure of $\beta$-globin chains synthesis. TM can lead to chronic hemolytic anemia so that patient's life will depend on transfusion. ${ }^{1-3}$ Cardiac complications such as heart failure and arrhythmias caused by iron induced cardiomyopathy, are considered as the primary cause of death in patients with TM. ${ }^{4}$ Little is known about pathophysiology of the heart involvement in TM. ${ }^{5}$ However the role of free radical hydroxyl in causing tissue damage has been widely accepted. ${ }^{6,7}$ Left ventricular functions in patients with TM have been detected by echocardiography. Nevertheless, these findings are somewhat conflicting. ${ }^{8,9}$

The importance of echocardiography is getting more visible when the ability to provide more sophisticated equipment is limited. The technique used to check heart functions of TM patients is the nuclear study which is fairly sensitive and dependable. Yet, this technology is extremely complex and too costly to apply in developing countries. ${ }^{10}$ The aim of this

From the Department of Child Health, Medical School, University of Indonesia, Jakarta, Indonesia.

Print request to: Muhammad Ali, MD, Department of Child Health, Medical School, North Sumatera University, Adam Malik Hospital, Jl. Bunga Lau No. 17, Medan, Indonesia. Tel/Fax. 62-61-8361721. Email: abijee69@yahoo.com. 
study was to evaluate left ventricular functions and mass alterations, and to find a correlation between echocardiographic findings and hematological data of patients with TM.

\section{Methods}

A cross-sectional study on 32 children with TM was conducted in Thalassemia Centre Cipto Mangunkusumo (CM) Hospital, Jakarta, from August 2005 to December 2005. Ethical approval was obtained from the Medical Ethics Committee, Medical School, University of Indonesia. Adolescents and young adults with TM who received multiple blood transfusions included in this study. Twenty-five healthy adolescents and young adults were employed as control. The minimal number of subjects needed for this research was 28 . The subjects were included if they had no clinical signs of cardiac dysfunction or pulmonary hypertension on echocardiography and had approval from their parents or guardian. The subjects were excluded if they were suffering from any other congenital malformations, taking cardio-active drugs, and presenting major endocrine disorders such as diabetes or hypothyroidism.

The following clinical and hematological data were obtained: age at diagnosis, mean pretransfusion hemoglobin concentration during the previous year, mean serum ferritin concentration, total blood transfusion, history of splenectomy, and compliance to chelating therapy.

We used Agilent Sonos 4500 with $8 \mathrm{MHz}$ transducer for echocardiographic examination. Complete cross-sectional echocardiography imaging of all cardiac chambers was done to exclude congenital abnormalities and significant valve lesions. Echo Doppler and Mmode were used to evaluate left ventricular systolic functions: ejection fraction (EF), fractional shortening (FS), diastolic functions: A, E, E/A ratio, isovolemic relaxation time (IVRT), and left ventricular mass: left ventricular diastolic dimension index (LVDDi), left ventricular systolic dimension index (LVSDi), left ventricular mass index (LVMi). Every subject was examined by two observers; each of them gave 3 examinations recorded into a VHS video tape. The reported results were the average of all examinations.

The statistic program used for data processing was SPSS version 10. Data was presented as mean (SD). Two samples of $t$ test were used to assess the differences between the variables in patients with TM and control subjects. Differences were considered significant at a probability value of $\mathrm{P}<0.05$. Hematological and echocardiography findings were tested using linear regression analysis, hematological data, and $\mathrm{E} / \mathrm{A}$ ratio of the left ventricular was tested using multiple regression analysis.

\section{Results}

From 58 subjects participating in the study, 32 were males and 26 were females. Thirty-three subjects were adolescents and the others were young adults. Two subjects with TM were excluded from the study because one of them suffered from VSD, and the other one was on the medication of heart disease (digitalis and furosemide).

Demographic data of TM and healthy controls are summarized in Table 1. Weight, height, and body surface area were significantly smaller in TM. Systolic,

Table 1. Demographic data of TM patients and Control

\begin{tabular}{lccc}
\hline Variable & TM $(\mathbf{n}=\mathbf{3 0})$ & Control $(\mathbf{n = 2 8 )}$ & $\mathbf{P}$ \\
\hline Age (years) & $18.1(5.1)$ & $17.7(5.3)$ & 0.73 \\
Body weight $(\mathrm{kg} / \mathrm{s})$ & $35.3(8.8)$ & $41.4(10.9)$ & 0.022 \\
Body weight $(\mathrm{cm} / \mathrm{s})$ & $146.5(11.9)$ & $153.3(12.7)$ & 0.043 \\
BSA $\left(\mathrm{m}^{2}\right)$ & $1.19(0.19)$ & $1.31(0.22)$ & 0.034 \\
SBP $(\mathrm{mmHg})$ & $102.7(8.1)$ & $108.4(8.9)$ & 0.014 \\
DBP $(\mathrm{mmHg})$ & $60.2(9.8)$ & $70.5(6.7)$ & $<0.0001$ \\
MBP $(\mathrm{mmHg})$ & $82.3(9.2)$ & $89.8(6.9)$ & 0.001 \\
HR (times/m) & $100.1(13.6)$ & $75.3(9.4)$ & $<0.0001$ \\
\hline
\end{tabular}

Value is mean (SD), BSA = body surface area, $\mathrm{SBP}=$ systolic blood pressure, $\mathrm{DBP}=$ diastolic blood pressure, $\mathrm{MBP}=$ mean blood pressure, $\mathrm{HR}=$ heart rate. 
diastolic, and mean blood pressure were lower in TM, while heart rate was faster. The hematological data of the TM patients are shown in Table 2. The mean of pretransfusion hemoglobin concentration was 7.4 (SD $0.8) \mathrm{g} / \mathrm{dl}$, and the mean of serum ferritin concentration was 7301.9 (SD 3788.2) ng/ml. Only a third of these patients showed good compliance to iron chelating treatment. Seven patients had undergone splenectomy.

In the TM patients, EF and FS were decreasing and smaller than the control. Concerning diastolic functions, significant differences were found in all variables, except for the variable $A(P>0.05)$. The mean of E, E/A ratio and IVRT of TM were greater than the control. We also found significant difference of left ventricle mass, systolic and diastolic dimensions which was corrected with the body surface area, between the TM and the control $(\mathrm{P}<0.05)$ (Table 3).

A strong and significant correlation was found between $\mathrm{E} / \mathrm{A}$ ratio and the serum ferritin concentration $(r=0.71 ; \mathrm{P}<0.0001)$ (Figure 1). There was no correlation between EF and serum ferritin concentration $(\mathrm{r}=-0.16 ; \mathrm{P}=0.933)$ as was the correlation be-

Table 2. Hematological data of TM patients

\begin{tabular}{lc}
\hline Age at the time of diagnosis, yrs & $1.4(1.5)$ \\
Duration of illness, yrs & $16.7(4.9)$ \\
Hemoglobin, g/dl & $7.4(0.8)$ \\
Ferritin serum, ng/ml & $7301.9(3788.2)$ \\
Duration of transfusion treatment, yrs & $15.8(5.3)$ \\
Total blood transfusion, ml & $85189.5(43087.8)$ \\
Splenectomy, yes/no & $7 / 23$ \\
Iron chelating therapy, yes/no & $30 / 0$ \\
Duration of iron chelating therapy, yrs & $10.1(5.7)$ \\
Compliance to iron chelating therapy, yes/no & $10 / 20$ \\
\hline
\end{tabular}

Value is mean (SD) tween LVMi and serum ferritin concentration $(r=0.135 ; \mathrm{P}=0.238)$. The results of multiple linear regression analysis of E/A ratio in TM are shown in Table 4. Only serum ferritin concentration showed a strong correlation with $\mathrm{E} / \mathrm{A}$ ratio (regression coefficient $\beta=0.71$ ).

Table 4. The Results of multivariate Regression analySIS TOWARDS E/A RATIO DETERMINANT IN TM

\begin{tabular}{lcc}
\hline Variable & $\begin{array}{c}\text { Regression } \\
\text { coefficient } \boldsymbol{\beta}\end{array}$ & $\mathbf{P}$ \\
\hline Age at the time of diagnosis & -0.21 & 0.132 \\
& & \\
Duration of illness & 0.11 & 0.280 \\
Hemoglobin & 0.24 & 0.922 \\
Ferritin serum & $\mathbf{0 . 7 1}$ & $<0.0001$ \\
Duration of transfusion & 0.49 & 0.398 \\
Total blood transfusion & 0.17 & 0.184 \\
Iron chelating therapy & 0.16 & 0.189 \\
\hline
\end{tabular}

\section{Discussion}

Recent study found that mean of pretransfusion hemoglobin concentration in TM patients was $7.4 \mathrm{~g} / \mathrm{dl}$ and was the lowest among that of other studies. ${ }^{11-13}$ This is much unpleasant, because chronic anemia state leads to awful cardiovascular effect. ${ }^{14,15}$ In contrast, serum ferritin concentration of TM in our study $(7301.9 \mathrm{ng} / \mathrm{ml})$ is the highest compared to that of other studies. ${ }^{11-13}$ This condition is also unfavorable. According to Olivieri study, ${ }^{16}$ cardiovascular condition of TM patients would be very good if ferritin concentration could be kept less than $2500 \mathrm{ng} / \mathrm{ml}$. This value had been fixed as a 'safe' concentration. We also detected that only three of TM patients were compli-

Table 3. Cardiology data of TM patients

\begin{tabular}{lccc}
\hline Variable & TM $(\mathbf{n}=\mathbf{3 0})$ & Control $(\mathbf{n}=\mathbf{2 8})$ & $\mathbf{P}$ \\
\hline Systolic functions & & & \\
EF, \% & $66.1(4.9)$ & $71.6(5.6)$ & $<0.0001$ \\
FS, \% & $36.0(3.7)$ & $39.8(5.5)$ & 0.003 \\
Diastolic functions & & & \\
$\quad$ E, cm/s & $118.6(15.2)$ & $95.9(14.7)$ & $<0.0001$ \\
A, cm/s & $56.7(9.8)$ & $52.6(8.8)$ & 0.102 \\
E/A ratio & $2.14(0.4)$ & $1.83(0.3)$ & 0.002 \\
IVRT, msec & $72.7(12.7)$ & $62.0(7.9)$ & $<0.0001$ \\
Mass & & & \\
LVDDi, mm & $35.1(5.4)$ & $31.4(4.8)$ & 0.008 \\
LVDSi, mm & $22.1(3.6)$ & $18.9(3.5)$ & 0.001 \\
LVMi, g/m & $111.1(30.8)$ & $75.4(14.5)$ & $<0.001$ \\
\hline
\end{tabular}

Value is mean (SD) 
Muhammad Ali et al: LV functions and mass in adolescents with thalassemia major

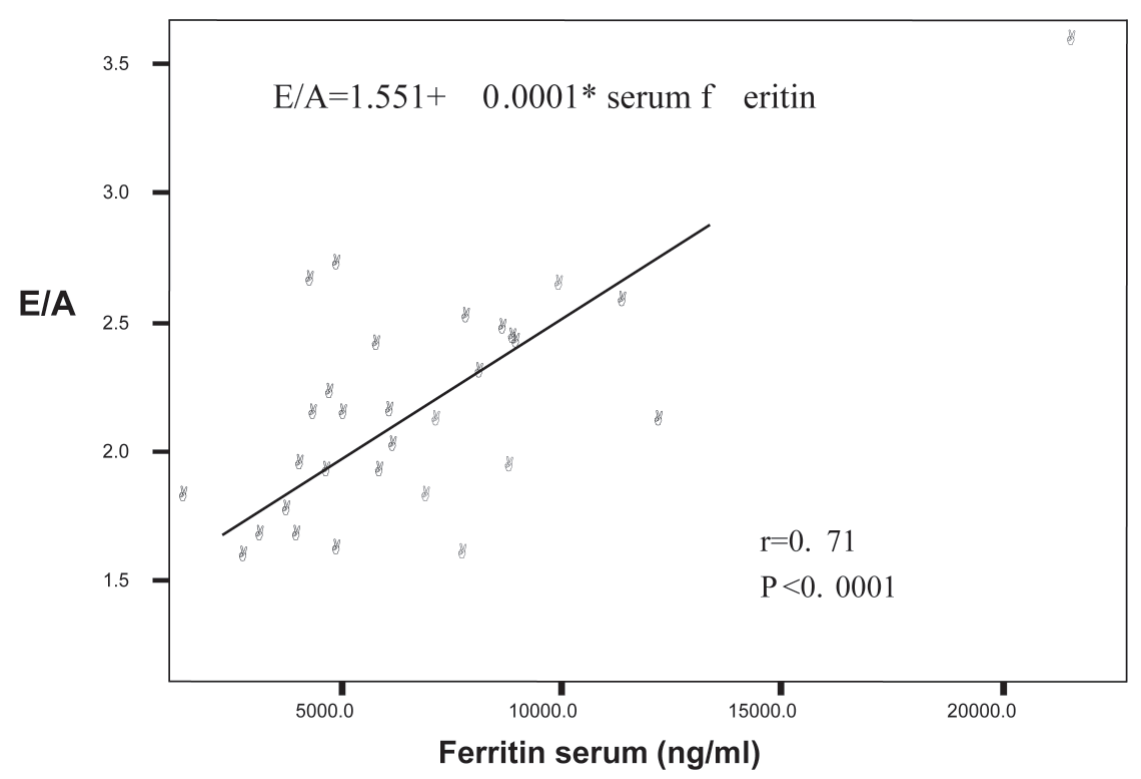

Figure 1. Correlation between E/A ratio and serum ferritin concentration

ance to the proper use of deferoxamine, which was very different from that of Olivieri et al. ${ }^{17}$ This study showed that left ventricular systolic and diastolic functions of TM were significantly lower than those of the control. This result is consistent with that reported by others. ${ }^{11,12,18,19}$

This study showed that in adolescents and young adults with TM with no clinical signs of cardiopulmonary involvement, there were alterations and abnormalities of left ventricular functions and mass. The decrease in left ventricular systolic performance is caused by increase in the afterload and a decrease in contractile state, and this may be secondary to iron toxicity. ${ }^{12,20-22}$

In the study of left ventricular diastolic functions, an increase in $\mathrm{E} / \mathrm{A}$ ratio indicated a decrease in left ventricular compliance, as a characteristic sign of restrictive myocardium process. ${ }^{23,24}$ The results of our study correspond with that of other studies. $9,11,12,25,26$ In contrast, no alteration of left ventricular compliance was reported in early stage of the disease as found by Kremastinos et al. 8,27 According to Spirito, ${ }^{9}$ the decrease of left ventricular compliance lead to diastolic dysfunctions because of myocardium damage which is induced by iron toxicity. Our study found that diastolic abnormality of left ventricle started to appear in the second decade of TM life and it could be found before other manifestations exist such as systolic abnormality and clinical sign of heart failure.

We also found that left ventricular mass in TM was significantly heavier than that of control. Henry found that an increase of thickness of wall and mass was a typical features TM. ${ }^{28}$ Our study's results were similar with those of other studies. ${ }^{11,12,25,29}$ In patients with TM, left ventricular resizing can be induced by intensive iron chelating therapy done in the right procedures. ${ }^{30,31}$

We found strong and significant correlation between E/A ratio and serum ferritin concentration $(\mathrm{r}=0.71 ; \mathrm{P}>0.0001)$. We also found a regression equation: $\mathrm{E} / \mathrm{A}=1.551+0.0001^{*}$ serum ferritin. It means that the higher serum ferritin concentration, the higher the E/A ratio is and the more likely TM patients to experience diastolic dysfunctions. No other hematological data were significantly and strongly correlated to echocardiography findings. This finding differs from that of Bosi et al. ${ }^{12}$ Patients with high serum ferritin concentration had low $\mathrm{EF}(\mathrm{r}=-0.23$ with $\mathrm{P}<0.001$ ). From Bosi's study ${ }^{12}$ and ours, we note that serum ferritin was a predictive factor, but the study of Piga et $a^{32}$ showed a contradictory results. They found that the serum ferritin concentration was not a predictor for the development of heart dysfunctions in TM patients. 
We conclude that left ventricular functions and mass of adolescents and young adults with TM show alterations and abnormalities. The higher the serum ferritin concentration, the more likely TM patients to suffer from diastolic dysfunctions.

\section{References}

1. Aessopos A, Farmakis D, Karagiorga M, Voskaridou E, Loutradi A, Hatziliami A, et al. Cardiac involvement in thalassemia intermedia: A multicenter study. Blood 2001;97:3411-6.

2. Gibbons R, Higgs DR, Olivieri NF, Wood WG. The âthalassemias. In: Weatherall DJ, Clegg JB, editors. The thalassemia syndrome. 4th ed. London: Blackwell Science; 2001. p. 287-300.

3. Honig GR. Hemoglobin disorders. In: Behrman RE, Kliegman RM, Jenson HB, editors. Nelson textbook of pediatrics. 16th ed. Philadelphia: W.B. Saunders Company; 2000. p. 1484-5.

4. Borgna-Pignatti C, Rugolotto S, De Stepano P, Piga A, Di Gregorio F, Gamberini MR, et al. Survival and disease complications in thalassemia major. Ann NY Acad Sci 1998;850:227-31.

5. Jessup M, Manno CS. Diagnosis and management of iron-induced heart disease in cooley's anemia. Ann NY Acad Sci 1998;850:242-50.

6. Caddel JL. Metabolic and nutritional diseases and diseases. In: Allen HD, Gutgessel HP, Clark EB, Driscoll DJ, editors. Moss and Adam heart disease in infants, children, and adolescents. 6th ed. Philadelphia: Lippincott Williams \& Wilkins; 2001. p. 1263-4.

7. Olivieri NF. The $\beta$-thalassemias. N Engl J Med 1999;341:99-109.

8. Kremastinos DT, Tsiapras DP, Tsetsos GA, Rentoukas EI, Vretou HP, Toutouzas PK. Left ventricular diastolic Doppler characteristics in â-thalassaemia major. Circulation 1993;88:1127-35.

9. Spirito P, Lupi G, Melevendi C, Vecchio C. Restrictive diastolic abnormalities identified by Doppler echocardiography in patients with thalassemia major. Circulation 1990;82:88-94.

10. Hoffband AV. A sensitive test for early myocardial loading. Eur Heart J 2003;24:26-7.

11. Vaccari M, Crepaz R, Fortini M, Gamberini MR, Scarcia S, Pitscheider W, et al. Left ventricular remodeling, systolic function, and diastolic function in young adults with $\beta$-thalassemia intermedia. Chest 2002;121:506-12.

12. Bosi G, Crepaz R, Gamberini MR, Fortini M, Scarcia $\mathrm{S}$, Bonsante $\mathrm{E}$, et al. Left ventricular remodeling, and systolic and diastolic function in young adults with âthalassaemia major: A Doppler echocardiographic assessment and correlation with hematological data. Heart 2003;89:762-6.

13. Kremastinos DT, Tiniakos G, Theodorakis GN, Katritsis DG, Toutouzas PK. Myocarditis in â-thalassemia major. Circulation 1995;91:66-71.

14. Metivier F, Marchais SJ, Guerin AP, Pannier B, London GM. Pathophysiology of anaemia: Focus on the heart and blood vessels. Nephrol dial transplant 2000;15(suppl 3):14-8.

15. Varat MA, Adolph RJ, Fowler NO. Cardiovascular effect of anemia. Am Heart J 1972;83:415-26.

16. Olivieri NF, Nathan DG, MacMillan JH, Wayne AS, Liu PP, McGee A, et al. Survival in medically treated patients with homozygous $\beta$-thalassemia. N Engl J Med 1994;331:574-8.

17. Olivieri NF, Brittenham GM. Iron-chelating therapy and the treatment of thalassemia. Blood 1997;89:739. 61.

18. Lau KC, Li AMC, Hui PW, Yeung CY. Left ventricular function in $\beta$-thalassaemia major. Arch Dis Child 1989;64:1046-51.

19. Bhal VK, Malhotra OP, Kumar D, Agarwal R, Goswami $\mathrm{KC}$, Bajaj R, et al. Non invasive assessment of systolic and diastolic left ventricular function in patients with chronic severe anemia: A combined m-mode, two-dimensional, and Doppler echocardiographic study. Am Heart J 1992;124:1516-23.

20. Valdes-Cruz LM, Reinecke C, Rutkowski M, Dudell GG, Goldberg SJ, Allen HD, et al. Preclinic abnormal segment cardiac manifestations of thalassemia major in children on transfusion-chelation therapy; echographic alteration of left ventricular posterior wall contraction and relaxation patterns. Am Heart J 1982;103:505-11.

21. Leon MB, Borer JS, Bacharach SL. Detection of early cardiac dysfunction in patients with severe $\beta$ thalassaemia and chronic iron overload. N Engl J Med 1979;301:1143-8.

22. Borow KM, Propper R, Bierman FZ, Grady S, Inati A. The left ventricular end-systolic pressure-dimension relation in patients with thalassemia major. A new noninvasive method for assessing contractile state. Circulation 1982;66:980-5. 
23. Grisaru D, Rachmilewitz EA, Mosseri M, Gostman M, Lafair JS, Okon E, et al. Cardiopulmonary assessment in beta thalassaemia major. Chest 1990;98:1138-42.

24. Appleton CP, Hatle LK, Popp RL. Demonstration of restrictive ventricular physiology by Doppler echocardiography. J Am Coll Cardiol 1988;11:757-68.

25. Cheung YF, Chan GCF, Ha SY. Arterial stiffness and endothelial function in patients with â-thalassemia major. Circulation 2002;106:2561-6.

26. Lattanzi F, Belloti P, Picano E, Chiarella F, Mazzarisi A, Melevendi C, et al. Quantitative ultrasonic analysis of myocardium in patients with thalassemia major and iron overload. Circulation 1993;87;748-54.

27. Kremastinos DT, Rentoukaas E, Mavrogeni S. Left ventricular inflow pattern in â-thalassemia major: A Doppler echocardiographic study. Eur Heart J 1993;14:351-7.

28. Henry WL, Nienhuis WA, Wiener M, Miller R, Canale VC, Piomelli S. Echocardiographic abnormalities in patients with transfusion-dependent anemia and secondary myocardial iron deposition. Am J Med 1978;64:547-55.

29. Aldouri MA, Wonke B, Hoffbrand AV, Flynn DM, Ward SE, Agnew JE, Hilson AJ. High incidence of cardiomyopathy in beta-thalassaemia patients receiving regular transfusion and iron chelation: Reversal by intensified chelation. Acta Haematol 1990; 84;113-7.

30. Pennell DJ. Iron overload and the heart. Hematology 2004;2004:20-9.

31. Politi A, Sticca M, Galli M. Reversal of haemochromatotic cardiomyopathy in beta thalassaemia by chelation therapy. British Heart Journal 1995;73:486-7.

32. Piga A, Gaglioti C, Fogliocco E, Tricta F. Comparative effects of deferiprone and deferoxamine on survival and cardiac disease in patients with thalassemia major: A retrospective analysis. Haematologica 2003; 88(05):489-96. 